\title{
SURVEY MOBILE APP
}

\author{
Trupti Kalkar $^{1}$, Sneha Akre ${ }^{2}$, Ashwini Gudadhe ${ }^{3}$, Megha Dhundale ${ }^{4}$ \\ ${ }^{1,2,3,4}$ Student, Information Technology, Rajiv Gandhi College of Engg, Nagpur, Maharashtra, India
}

\begin{abstract}
From a long time different surveys are carried to get some kind of stats related to particular survey. But these surveys involve lot of manual methods and huge amount of human intervention which sometimes causes delays in the surveys. To make use of our App in Government sector and to reduce the work done manually for different market surveys done by the different Organizations. The main motive of choosing this topic was to make our product work in Android Mobiles.
\end{abstract}

This is a Survey Mobile App basically will be used in public and private sectors of any Organizations. This App is used to reduce the workload of any employee who does his work manually. This app will allow us to make surveys of different type from just one single mobile app.This App will help him to do his work in more convenient manner.

Keywords: Marketing, Survey, Android, ASP.NET, Phone Gap, JQuery.

\section{INTRODUCTION}

\subsection{Definition of Surveys}

1. Marketing: A detailed study of a market or geographical area to gather data on attitudes, impressions, opinions, satisfaction level, etc., by polling a section of the population.

2. Real_estate: A map or plat drawn by a licensed-surveyor after measuring a piece of land, to show its area, boundaries, contours, elevations, improvements, and its relationship to the surrounding land. A property survey confirms that a particular piece of land or building is sited in accordance to its legal description.

\section{Types of surveys}

- Face-to-face interviews.

- Phone interviews

- Written questionnaire

\subsection{Categories of Surveys}

- Customer Satisfaction Surveys

- Employee Satisfaction Survey

- HR Survey \& Training Surveys

- Business Survey

- Marketing Survey

- Market Research Survey

- Student Survey, Teacher Survey, School Survey

- Non-Profit Survey

- Meeting Survey \& Event Planning Survey

- Product Feedback Surveys

\subsection{Characteristics of Survey}

- Present or proposed practices or program are questioned.

- A comprehensive study and evaluation is made of the status of all factors relating to the practices or programs questioned.

- Both immediate and future needs are stated as they are indicated by the status study and research findings.

- Practices or programs are outlined to meet the needs

Surveys may be classified in a number of ways, as for example: scope, comprehensive or limited; agency, outside or internal. The following classification has proved most helpful to the writer. Brief comments will be made about each type of survey.

\section{LITERATURE SURVEY}

\subsection{What is a Survey?}

\subsection{Android}

An open source Linux based operating system, Android was Purchased by Google in 2005[16]. Android was founded with the Open Handset Alliance, and finally released for mobile devices such as Smartphone and sold it's first easy for developers to program the device in languages such as $\mathrm{C}, \mathrm{C}++$ and Java. Google also provides a freely available Software development kit (SDK) to facilitate application creation. Android powered devices have grown to be a common sight internationally today, leading the global Smartphone marketplace share for mobile operating systems as of early 2013 at approximately 70\% [19]. Android has seen numerous 
updates spanning from version 1 through 4.2 . x providing new features, performance boost, design changes, as well security patches.

There's no other software quite like Android. Google Engineered Android and Google's own apps run best on it. And with millions of apps, games, songs, and videos on Google Play, Android is great for fun, and for getting things Done

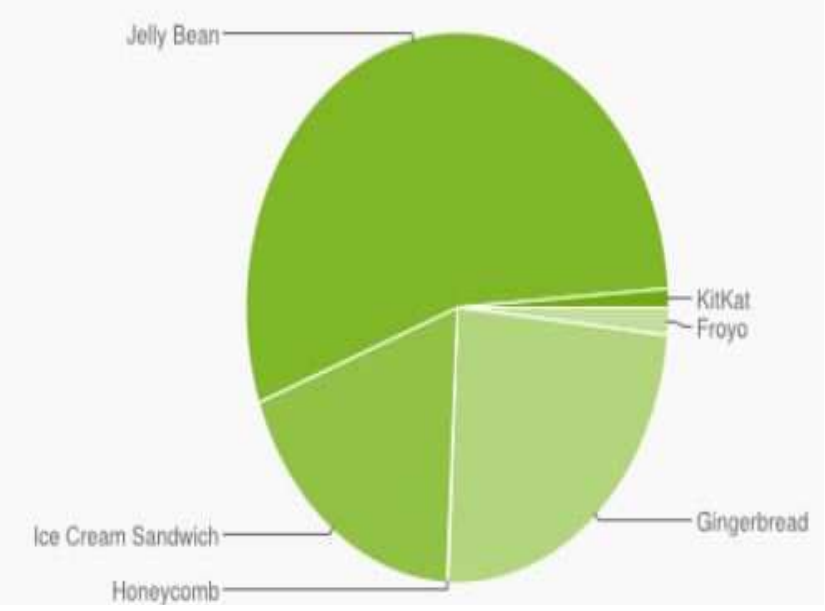

Android devices come in all kinds of sizes, with all sorts of features, and at all sorts of prices. Each version of Android is named after a dessert, and the most recent version of Android is Jelly Bean. With Android, you're in control of your mobile experience.

With the enormous popularity and growth of the Android platform has seen since its inception, it not surprising that it's become a more lucrative target for malware designers.

The Android platform is designed to allow developers to use core device functionality such as the text messages and the calling features. The Android platform debuted on only 1 phone on one carrier and now is offered on hundreds of phone across every major carrier. In recent years the number of mobile malware on the Android platform has begun alarming security experts and customers alike. During the 3rd quarter of 2012 a security group F-Secure detected over 51,000 malware instances an increase by 10 folds from the previous $2^{\text {nd }}$ quarter where only approximately 5,000 instances. Among them only 146 were from the Google Play store.

The growth and a adoption rate for Android has seen a positive increase since its debut and with 2009-quarter estimates from a research company analysis showing $2.8 \%$ market share to a dominating $70 \%$ in the first quarter in 2013. Google reported in 2011, that there were 550,000 activations daily and growing by approximately $4.4 \%$ per week. It was these kinds of number that attracted such a large malware developing community for PCs. Android today can be seen used in to the latest versions has meant that many of these vulnerabilities have remained throughout the updates. A sample was taken using data from Google's Play store to get a representative measure on the distribution of different currently being used. International communities such as South America and China even though China has had limited access to Google services including the Google Play store.

The evolution of the Android platform has seen several version changes from 1.x when first revealed in 2007 and now its latest iterations as of early 2013 codename Jelly Bean version 4.x.x. Each version has added new features and boasted overall performance as well as closing security holes and resolving vulnerabilities. Unfortunately, a slow adaption to the latest versions has meant that many of these vulnerabilities have remained throughout the updates. A sample was taken using data from Google's Play store to get a representative measure on the distribution of different currently being used.

\begin{tabular}{|c|c|c|c|}
\hline Version & Codename & API & Distribution \\
\hline 2.2 & Froyo & 8 & $1.6 \%$ \\
\hline $\begin{array}{l}2.3 .3- \\
2.3 .7\end{array}$ & Gingerbread & 10 & $24.1 \%$ \\
\hline 3.2 & Honeycomb & 13 & $0.1 \%$ \\
\hline $\begin{array}{l}4.0 .3- \\
4.0 .4\end{array}$ & $\begin{array}{l}\text { Ice Cream } \\
\text { Sandwich }\end{array}$ & 15 & $18.6 \%$ \\
\hline 4.1. $x$ & \multirow[t]{3}{*}{ Jelly Bean } & 16 & $37.4 \%$ \\
\hline $4.2 . x$ & & 17 & $12.9 \%$ \\
\hline 4.3 & & 18 & $4.2 \%$ \\
\hline 4.4 & KitKat & 19 & $1.1 \%$ \\
\hline
\end{tabular}

Data collected during ending of December 2013. Versions with less than $0.1 \%$ distribution are not shown.

$\square \square$ Take Google with you

$\square \square$ Your stuff, always available, no wires needed

$\square \square$ Play everywhere you go

- Powerful, simple, and beautiful

- Multi-tasking

- Voice typing and actions

- Photos and videos

- Beyond Smart

\subsection{ASP.net}

ASP.NET is a server-side Web application framework designed for Web development to produce dynamic Web pages. It was developed by Microsoft to allow programmers to build dynamic web sites, web applications and web services. It 
was first released in January 2002 with version 1.0 of the .NET Framework, and is the successor to Microsoft's Active Server Pages (ASP) technology. ASP.NET is built on the Common Language Runtime (CLR), allowing programmers to write ASP.NET code using any supported .NET language. The ASP.NET SOAP extension framework allows ASP.NET components to process SOAP messages.

\subsection{Characteristics of ASP.Net}

ASP.NET Web pages, known officially as Web Forms are the main building blocks for application development. Web forms are contained in files with a ".aspx" extension; these files typically contain static (X) HTML markup, as well as markup defining server-side Web Controls and User Controls where the developers place all the rc content [further explanation needed] for the Web page. Additionally, dynamic code which runs on the server can be placed in a page within a block $<\%$ - dynamic code -- \%>, which is similar to other Web development technologies such as PHP, JSP, and ASP. With ASP.NET Framework 2.0, Microsoft introduced a new codebehind model which allows static text to remain on the aspx page, while dynamic code remains in an .aspx.vb or .aspx.cs or aspx.fs file (depending on the programming language used).

\section{DESIGN}

\subsection{Implementation}

- Creating survey using custom patterns and database architecture:

User can create surveys by entering survey title and different types of categories of survey he is creating. After clicking on Add Question button slide box will take place which will include Question text and Question type. Depending upon the type of Question selected the related text box will be drawn out for the user. The included information will be loaded into database tables.

- Survey modification and monitoring system: Surveys can be updated by deleting, modifying, renaming acording to the user and new survey can be created again.

- Category of survey to be updated if needed:

If the user want to insert new categories in the types of categories list during run time he will be able to do so.

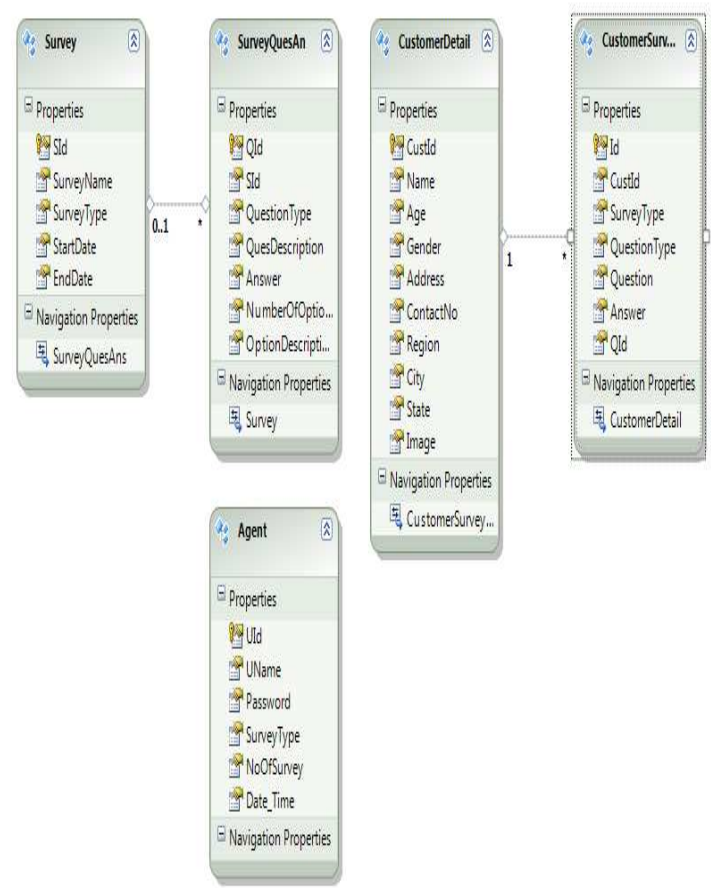

\section{METHODOLOGY}

- The technique that is of prime importance and will be used with Android Mobile App is Phone Gap. This framework allows us to create HTML pages that can be rendered in a particular mobile app. Phone Gap latest version that is to be used is 2.2.0. Along with that Android SDK will be used to provide communication medium between Android OS and Phone Gap framework.

- Later part of this project will include server based functionalities which will be implemented in .Net Framework. It will also contain Web Services made in .Net Framework and most interesting part will interaction between these web services and Android mobile App i.e. communication of two different platforms. 

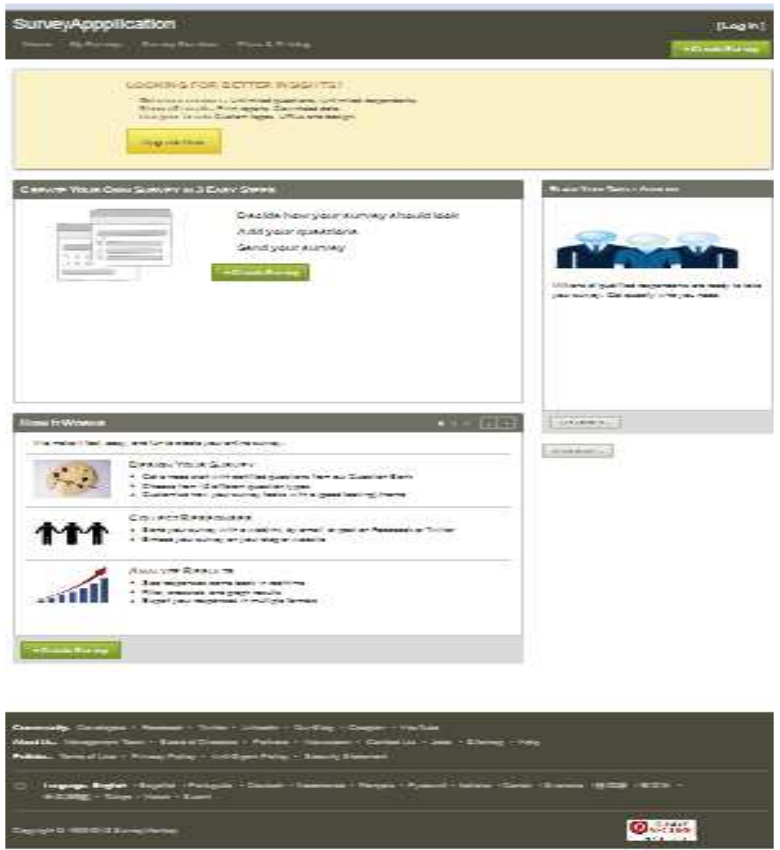

Fig 1: Home Page

Description of Fig 1: Fig 1 shows the home page of our application. In includes three create buttons and login button by which the user can login and create $n$ use surveys made by him.

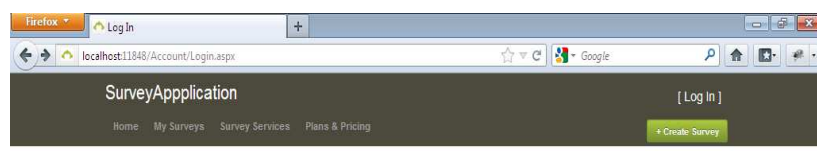

LoG IN

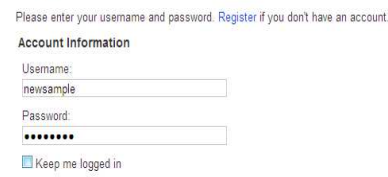

पKeep mel loged in

Login

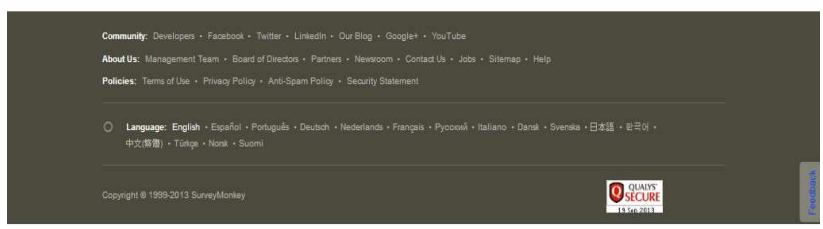

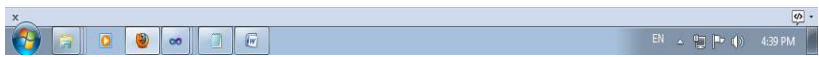

Fig 2: Login Page

Description of Fig 2: The second page include login page in which the user would get the facility to create different kind of surveys. Login page will include user id and his password.

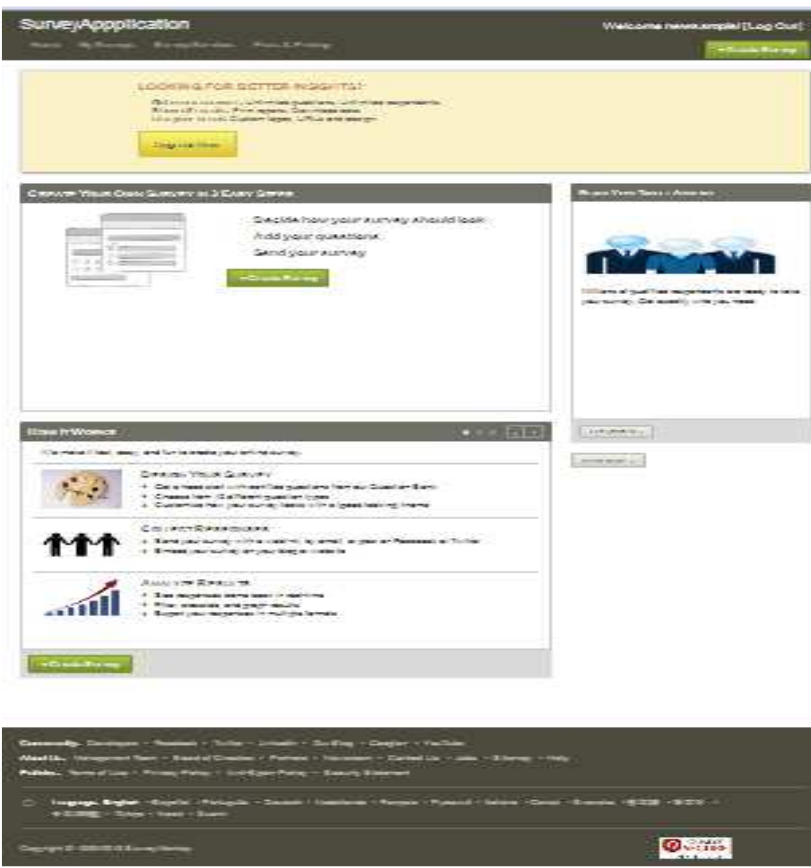

Fig 3: Welcome usser Login Page

Description of Fig 3: In fig 3 the user will use his account and form surveys and after using his account he can logout. One user can create many surveys.

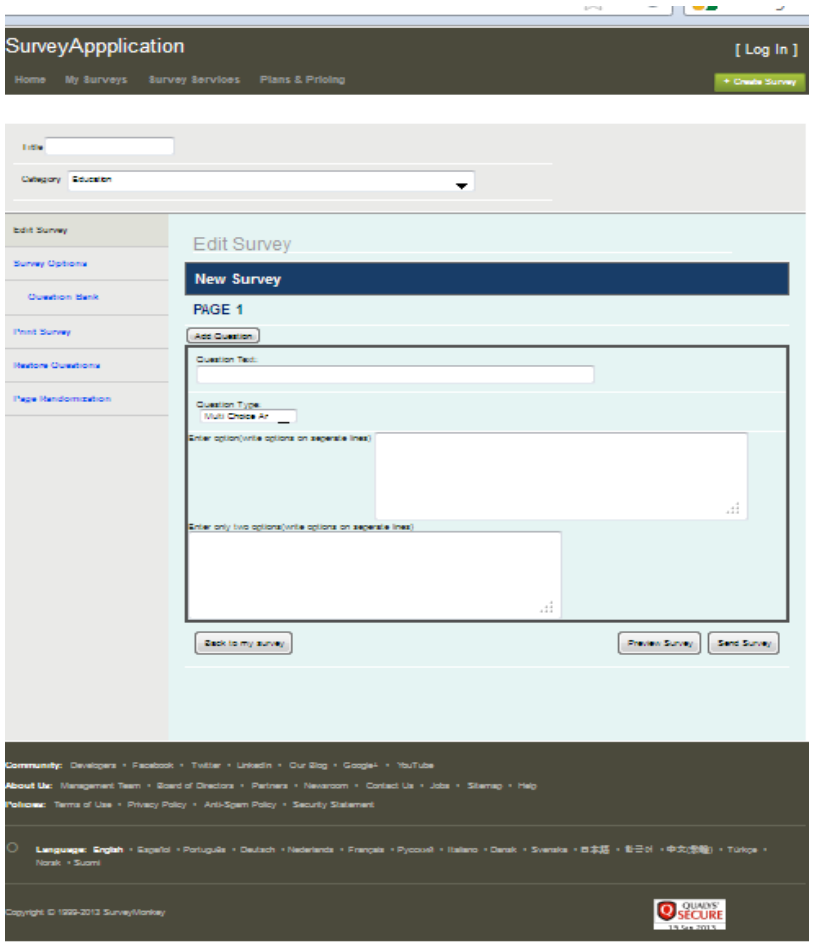

Fig 4: Survey Creation Page 
Description of Fig 4: In fig 4 users can create surveys by entering survey title and different types of categories of survey he is creating. After clicking on Add Question button slide box will take place which will include Question text and Question type. Depending upon the type of Question selected the related text box will be drawn out for the user.

\section{CONCLUSIONS}

Thus we have almost completed the work of creating web pages and the database of our first phase successfully.

The future work of our project will be the pages created in the first phase will be loaded in the mobile from the server through connectivity.

\section{ACKNOWLEDGEMENTS}

Many people in, Rajiv Gandhi College of Engineering and Research (RGCER) College have supported us from the beginning of our B.E project work. Without them, the project would obviously not have looked the way it does now. Person we would like to thank is our Project Guide Mrs.Puja S Prasad, Professor of Information Technology, RGCER, Nagpur. She has helped us in many ways. Her enthusiastic engagements in our project work and her never-ending stream of ideas have been absolutely essential for the results, presented here. We are very grateful that she has spent so much time with us discussing different problems ranging from philosophical issues down to minute technical details.

\section{REFERENCES}

[1] http://source.android.com/

[2] http://www.androiddevelopers.com/

[3] http://developer.android.com/guide/components/index. html

[4] http://docs.phonegap.com/en/3.0.0/index.html

[5] http://www.w3schools.com/aspnet/webpages_intro.asp

[6] http://api.jquery.com/category/ajax/

[7] Beginning Android 4 Application Development.

[8] Android.Application.Development.For.Dummies

[9] Android-a programmer's guide

[10] Introduction-to-android-845

[11] Android Overview[Online] Available:

[12] http://www.openhandsetalliance.com/android_overvie w .html

[13] Professional Android Programming with Mono for Android and .NET/C\#

[14] Symantec. Android.geinimi.

[15] http://www.symantec.com/security_response/writeup.js p?docid=2011 010111-5403-99

\section{BIOGRAPHIES}

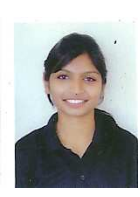

Trupti Kalkar study in Rajiv Gandhi College of Engineering and Research, in department of Information Technology 8th semester she is presented her 1 st intern national paper.

Email id: t.kalkar@gmail.com

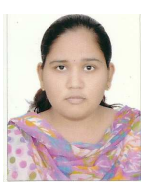

Sneha Akre study in Rajiv Gandhi College of Engineering and Research, in department of Information Technology 8th semester she is Presented the 1 international paper.

Email id: sneha.akre@gmail.com

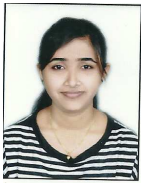

Ashwini Gudadhe study in Rajiv Gandhi College of Engineering and Research, in department of Information Technology 8th semester she is Presented the 1 international paper. Email id: gudadheashu@gmail.com

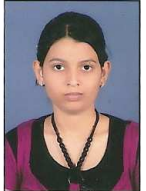

Megha Dhundale study in Rajiv Gandhi College of Engineering and Research, in department of Information Technology 8th semester she is Presented the 1 international paper.

Email id: dhundalemegha@gmail.com 